\title{
Repatologizando a homossexualidade: a perspectiva de "psicólogos cristãos" brasileiros no século XXI ${ }^{1}$
}

\section{Repatologizing homosexuality: the perspective of Brazilian "Christian psychologists" in the 21st century}

\section{Repatologizando la homosexualidad: la perspectiva de "psicólogos cristianos" brasileños em el siglo XXI}

\author{
Cleber Michel Ribeiro de Macedo* \\ Universidade do Estado do Rio de Janeiro - UERJ, Rio de Janeiro, Rio de Janeiro, \\ Brasil
}

\section{Horacio Federico Sívori**}

Universidade do Estado do Rio de Janeiro - UERJ, Rio de Janeiro, Rio de Janeiro, Brasil

\begin{abstract}
RESUMO
Este artigo trata da disputa gerada por profissionais identificados como "psicólogos cristãos" que defendem publicamente seu direito de oferecer auxílio terapêutico com o fim de reverter a homossexualidade. Esta polêmica adquiriu contornos particulares no Brasil, onde o Conselho Federal de Psicologia desde 1999 proíbe qualquer forma de patologização da orientação sexual. Com base na literatura especializada começamos por expor, por um lado, a trajetória da homossexualidade como objeto de discurso da Psicologia e, por outro, no campo evangélico. A seguir, explicamos a conformação da Psicologia como profissão regulamentada no Brasil. Em seguida, com base em fontes documentais de caráter público, examinamos a posição do Conselho Federal de Psicologia e analisamos as disputas jurídicas travadas por psicólogos que defendem seu direito a tratar a homossexualidade como expressão de desordem moral e desvio patológico. O antagonismo que emerge na polêmica em torno da chamada "cura gay" não opõe simplesmente ciência e religião, mas envolve atores públicos capazes de se localizar estrategicamente em um ou outro campo e de fazer uso do direito em seu favor. Sua capacidade de recolocar a homossexualidade como signo de desvio moral e transtorno mental constela a política sexual como questão de peso para a democracia brasileira.
\end{abstract}

Palavras-chave: evangélicos, homossexualidade, psicologia, religião, sexualidade.

\section{ABSTRACT}

This article examines the claims of professionals identified as "Christian psychologists" who publicly defend their right to offer therapy to "reverse homosexuality". This debate took shape when "conversion therapy" was banned by the Brazilian Federal Council of Psychology in 1999. Based on specialized literature, we begin by introducing, on the one hand, the 
itinerary of homosexuality as object of discourse in Psychology, and in the evangelical field, on the other. And we go on explaining the process of constitution of Psychology as a regulated practice in Brazil. Then, based on public records, we examine the stand taken by the Federal Council of Psychology, and analyze the legal claims made by psychologists who defend their right to treat homosexuality as a moral offense and a mental disorder. The antagonism that emerges in the so-called "gay cure" debate does not simply oppose science and religion but involves public actors capable of strategically placing themselves in one field or the other and use the Law in their favor. Their ability to consider homosexuality as a sign of moral deviance and a mental disorder places sexual politics as a significant issue with regards to Brazilian democracy.

Keywords: evangelicals, homosexuality, psychology, religion, sexuality.

\section{RESUMEN}

Este artículo aborda la disputa generada por profesionales identificados como "psicólogos cristianos" que defienden públicamente su derecho a ofrecer apoyo terapéutico con el fin de revertir la homosexualidad. Esta polémica adquirió contornos particulares en Brasil, donde el Consejo Federal de Psicología desde 1999 prohíbe cualquier forma de patologización de la orientación sexual. Basándonos en literatura especializada, comenzamos por exponer, por un lado, la trayectoria de la homosexualidad como objeto de discurso de la Psicología y, por otro, en el campo evangélico. A continuación, explicamos la conformación de la Psicología como profesión reglamentada en Brasil. Luego, basándonso en fuentes documentales de carácter público, examinamos la posición del Consejo Federal de Psicología y analizamos las disputas jurídicas entabladas por psicólogos que defienden su derecho a tratar la homosexualidad como expresión de desorden moral y desvío patológico. El antagonismo que emerge en la polémica en torno de la llamada "cura gay" no opone simplemente ciencia y religión, sino que involucra actores públicos capaces de localizarse estratégicamente en uno u otro campo y de hacer uso del derecho a su favor. Su capacidad de recolocar la homosexualidad como signo de desvío moral y trastorno mental constela la política sexual como cuestión de peso para la democracia brasileña.

Palabras clave: evangélicos, homosexualidad, psicologia, religión, sexualidad.

\section{I ntrodução}

Existem atualmente em diversos países profissionais do campo da saúde que justificam posicionamentos controversos acerca da homossexualidade por suas convicções religiosas. No Brasil o caso mais notório é o de "psicólogos cristãos" de filiação evangélica que defendem publicamente seu direito de oferecer auxílio terapêutico com o fim de reverter a homossexualidade. $O$ discurso que sustenta a oferta de tais tratamentos, vulgarizados como "cura gay", desafia tanto o consenso científico da Psiquiatria e da Psicologia, que nas últimas décadas do Século XX aboliram a classificação da homossexualidade como patologia, como o marco jurídico do Estado, que exige o reconhecimento igualitário da diversidade sexual. Neste 
artigo abordamos os significados que a controvérsia pública em torno da "cura gay" adquiriu no campo profissional da psicologia brasileira nas duas primeiras décadas do Século XXI. O caso brasileiro é único no mundo devido à existência de um instrumento da entidade que regula a prática da profissão, o Conselho Federal de Psicologia (CFP), que proíbe expressamente qualquer atividade conduzida por psicólogos que leve à patologização de identidades ou de comportamentos homossexuais: a Resolução CFP 01/99. Esta proibição contempla também ações que orientem homossexuais a tratamentos não solicitados, bem como a colaboração com serviços que promovam o "tratamento" ou a "cura" da homossexualidade. Profissionais identificados como "psicólogos cristãos" que defendem pautas morais conservadoras na política nacional têm desenvolvido intenso ativismo em resposta à Resolução de 1999, questionando a autoridade científica dos conselhos por diversas vias.

Neste artigo argumentamos que a disputa em torno da regulação da atuação profissional do psicólogo no que tange à diversidade sexual se configurou deste modo em função de modos específicos de regulação estatal e de politização da Psicologia como ciência e como profissão no Brasil, bem como do seu papel como palco de antagonismos que perpassam diversas arenas da política nacional. Assim, o atravessamento da identidade e prática profissionais por valores morais e dogmas religiosos e, sobretudo, a encenação pública de um debate que veicula argumentos pseudocientíficos que reconduzem a homossexualidade para o território do patológico só adquirem sentido se analisados como parte de um cenário maior, que constela a política sexual como questão de peso em processos políticos que afetam a democracia brasileira como um todo. Nesse contexto, a controvérsia sobre a "cura gay" ilustra o papel da produção do conhecimento, da expertise e da regulação do exercício de profissões do campo da Saúde, sobretudo no caso da Psicologia, com relação à mobilização de conviçcões religiosas na esfera política, em favor ou contra a abordagem da livre expressão e exercício da orientação sexual como direito humano.

De modo a construir as bases empíricas desse argumento com o auxílio de literatura das ciências sociais e humanas, começamos expondo três trajetórias encontradas neste enredo: a da categoria "homossexual" no campo psi; a da atuação religiosa evangélica com relação à homossexualidade; e a da Psicologia como profissão regulamentada no Brasil. A seguir, com base em fontes documentais de caráter público, impressas e principalmente eletrônicas, trazemos à tona os elementos da controvérsia em torno da "cura gay" no Brasil. Examinamos, em primeiro lugar, a atuação do Conselho Federal de Psicologia em defesa dos Direitos Humanos, da laicidade do exercício profissional e, em particular, contra a repatologização da homossexualidade. Em segundo lugar, abordamos as disputas 
travadas em torno da Resolução CFP 01/99 por psicólogos que defendem publicamente sua convicção de que a homossexualidade pode ser revertida e seu direito a tratá-la como expressão de desordem moral e desvio patológico. Finalmente, abordamos brevemente as trajetórias de duas profissionais, Rozangela Justino e Marisa Lobo, que foram sujeitas a processo ético por parte dos seus respectivos Conselhos Regionais de Psicologia por advogar publicamente em favor do acolhimento psicológico com o fim de reverter a homossexualidade. Nas considerações finais retomamos a discussão inicial acerca da disputa de regimes de moralidade que eclode na controvérsia sobre a "cura gay", dos impasses da relação entre Estado, ciência e religião, e do papel crítico da garantia do livre exercício da sexualidade para a convivência democrática.

\section{Breve histórico da categoria "homossexual"}

\section{A medicalização do "desvio": o “homossexualismo"}

No clássico "História da Sexualidade I - a vontade de saber", Michel Foucault (2014), postulou o 'nascimento' do "homossexual" como categoria psicológica, psiquiátrica e médica no século XIX. Ao longo do tempo, as definições do campo semântico em torno da categoria patológica "homossexualismo" foram mudando, adquirindo distintos matizes. Com o processo de secularização iniciado no Ocidente, em especial nos países de língua inglesa, a partir do final da idade média, a responsabilidade por controlar comportamentos moralmente inaceitáveis havia passado da Igreja para o sistema judiciário criminal (Kutchins \& Kirk, 1997). Curiosamente, no Brasil, um dos primeiros registros do termo "homossexualismo" não está no âmbito psiquiátrico, e sim na literatura, na novela Bom Crioulo, de Adolfo Caminha, de 1896 (Green, 1999).

Se durante o século XIX, a incipiente medicalização da existência humana suplantou a criminalização de muitas condutas tidas como imorais (Kutchins \& Kirk, 1997, p. 58), atualmente a disputa entre os paradigmas criminal e médico teria sido aparentemente superada, a distinção entre punição e tratamento se torna menos aparente do que frequentemente havia sido sugerido. "Tratamentos" para a "cura" da homossexualidade têm sido fonte de dificuldade, dor e dano para os homossexuais desde que a ideia de intervenção terapêutica começou a competir com a punição criminal durante o século XIX (Kutchins \& Kirk, 1997, p. 58).

Algumas intervenções terapêuticas a que homossexuais homens e mulheres foram submetidos a partir do século XIX, conforme compilaram Kutchins e Kirk (1997) consistem em intervenções cirúrgicas como castração, vasectomia, lobotomia, esterilização, 
clitorodectomia e histerectomia; intervenções químicas com estimulação sexual, indução de depressão sexual e injeção de hormônios (estrogênio e testosterona), e intervenções psicológicas, como a prescrição de abstinência, terapia de ajustamento, psicanálise, hipnose e terapia aversiva.

\section{A disputa pelas classificações}

Na primeira publicação do Manual Diagnóstico e Estatístico de Transtornos Mentais (DSM), pela Associação Americana de Psiquiatria (APA), em 1952, era notável a influência da psicanálise na organização e no diagnóstico dos distúrbios psíquicos. De acordo com essa concepção, havia três principais divisões dos distúrbios nãoorgânicos: psicose, neurose e desvio da personalidade. Nesse último grupo, incluía-se o desvio de sexualidade, que era o diagnóstico utilizado para se referir à homossexualidade (Kutchins \& Kirk, 1997).

À época o DSM era pouco utilizado e não existia um grande acolhimento ao manual tanto dentro quanto fora da APA, além de haver uma crescente insatisfação com o diagnóstico psiquiátrico entre os cientistas, os profissionais e o público em geral durante os anos de 1960. Esse descontentamento com o DSM foi encabeçado pela luta para eliminar o diagnóstico de "homossexualismo" (Kutchins \& Kirk, 1997). De acordo com Kutchins e Kirk (1997), há quatro vertentes que contribuíram para a retirada do "homossexualismo" do DSM, quais sejam: 1) mudanças históricas nas concepções de homossexualidade, 2) a emergência do movimento militante gay, 3) a transformação da psiquiatria e de sua organização profissional e, por fim, 4) uma disputa interna nesse campo a respeito da psicanálise.

Dessa forma, a saída da homossexualidade do DSM deve ser compreendida em um contexto mais amplo de debate em torno do esvaziamento da psicanálise na APA (Kutchins \& Kirk, 1997). A antropóloga Jane Russo (2004), ao examinar a conjuntura em que ocorreu essa transformação, destaca que nas últimas décadas do século XX, a visão "psicossocial" dos transtornos mentais sucumbiu a uma visão eminentemente biológica. Essa mudança não foi isolada, compreendendo uma espécie de "re-biologização" de temas e discussões que antes se referiam ao campo político, como as diferenças de gênero ou de raça. Nessas circunstâncias, em que se estreitam as relações entre o DSM III e a psicofarmacologia, é possível compreender a ampla difusão do novo manual no meio psiquiátrico mundial em contraste à sua edição anterior, o DSM-II. O DSM III tornou-se rapidamente uma espécie de "bíblia psiquiátrica" (Russo \& Venâncio, 2006, p. 465).

Nos Estados Unidos, a vitória do movimento gay deve ser compreendida em uma perspectiva que engloba outros movimentos 
de luta pelos direitos civis, como a luta dos movimentos feministas, o movimento dos negros e os protestos contra a guerra do Vietnã. A retirada do "homossexualismo" da segunda versão do manual psiquiátrico (DSM-II), publicado em 1968, não representou completamente o fim da patologização dessa categoria no compêndio psiquiátrico estadunidense. O DSM-III, publicado em 1980, voltou a apresentar resquícios dessa 'psiquiatrização'. O diagnóstico de "homossexualidade ego-distônica", que corresponde à condição atribuída ao homossexual em sofrimento com a sua atração sexual e que gostaria de se ver livre dessa condição (Dunker \& Kyrillos Neto, 2011), permaneceu até 1987, ano em que foi retirado, com a publicação revista do DSM III, o DSM III-R. Nesse caso não houve alarde, pois, a essa altura, o contexto político e social já era outro, distante dos embates dos anos de 1970 (Russo, 2005).

Conforme a interpretação de Conrad (2007), em contraste ao ativismo dos anos de 1970, que visava reduzir o estigma da homossexualidade, a emergência da epidemia de AIDS no início da década de 1980 renovou essa condição, com a imagem de uma doença associada ao estilo de vida de homens gays. Em decorrência da conexão com a homossexualidade, a resposta médica à AIDS foi uma via de mão dupla, por um lado, a negligência médica, por outro lado, a vigilância médica sobre o comportamento dos homens gays. A AIDS aumentou essa vigilância sobre o comportamento gay $e$ exacerbou a estigmatização da homossexualidade, sem tê-la necessariamente medicalizado como um todo ${ }^{2}$.

\section{Psicanálise e homossexualidade}

Dado ao escopo e ao objetivo deste artigo, não iremos investigar as complexas e diversas teorizações sobre homossexualidade e seus respectivos desdobramentos na psicanálise ${ }^{3}$. Não obstante, considerando sua relevância como Weltanschauung, que ultrapassa o âmbito psi, e perpassa o ocidente ao longo do século passado (Russo, 2002) bem como sua imbricação com a difusão da psicologia no Brasil, destacamos pontos que nos oferecem pistas sobre as concepções de homossexualidades no âmbito dessa disciplina.

Como observado anteriormente ao abordarmos a transformação na concepção, conteúdo e apresentação do DSM, ressalvamos o quanto as teorizações psicanalíticas estiveram atreladas a concepções psiquiátricas até os anos de 1960 - quando uma "revolução" farmacológica contribuiu para a reformulação dos paradigmas nesse campo, que influiu para o deslocamento da psicanálise do seu lugar de saber dominante no âmbito "psi" (Russo, 2002; Russo \& Venâncio, 2006).

Segundo Conrad (2007), no início do século XX, Sigmund Freud revolucionou $\mathrm{o}$ modo como a medicina e a psiquiatria definiam e 
tratavam uma ampla gama de problemas humanos. Freud concebia a homossexualidade em termos de sua teoria geral da sexualidade e rejeitava noções de etiologia congênita tão em voga à época. Para o pai da psicanálise, os desejos homoeróticos eram parte do desenvolvimento normal das crianças e apesar de a homossexualidade ser um "estado indesejável", sob a sua perspectiva ela era não mais que uma "variação" ao invés de uma doença ou distúrbio. Freud não acreditava que a homossexualidade pudesse ser modificada por tratamento médico ou por psicanálise (Ceccarelli, 2008, 2012; Freud, 2006, p. 52).

No entanto, alguns seguidores de Freud reestabeleceram a homossexualidade como 'doença psiquiátrica' sujeita a tratamento. A partir do início dos anos de 1940, três psiquiatras que adotaram alguma variação da teoria freudiana emergiram como os mais influentes defensores da perspectiva da "homossexualidade como doença" nos EUA, são eles: Edmund Bergler, Irving Bieber e Charles Socarides (Conrad, 2007). No contexto norte-americano, essas disputas sobre uma suposta gênese e tratamento de pacientes homossexuais foram parte de uma grande batalha na psicanálise (Kutchins \& Kirk, 1997; Drescher, 2013). Nos Estados Unidos, de acordo com o psiquiatra e psicanalista Jack Drescher (2013), enquanto a maioria dos psicanalistas e de todas as suas organizações profissionais sustentavam que a homossexualidade era uma condição patológica, houve dissidências, como as de Judd Marmor, para quem o status "diagnóstico de homossexualidade" é moral e Robert Stoller, para quem as teorias psicanalíticas confundiam identidade de gênero e orientação sexual.

Esse recorte - ainda que longe de abarcar a totalidade do tema no âmbito psi e das polêmicas que o rodeiam - oferece elementos que nos permitem inferir o quanto a "homossexualidade", nos variados usos e significados dessa categoria, é controversa na psicanálise e quão diversa é a concepção desse tema. Tanto desde as primeiras teorizações de Freud, no início do século XX, com os "Três ensaios sobre a teoria da sexualidade" (1905), quanto ao longo de toda a sua obra, para ficar em alguns exemplos - "Leonardo da Vinci e uma lembrança de sua infância" (1910), "O caso de Schreber" (1911) e "Psicogênese de um caso de homossexualismo numa mulher" (1920) - e, até 1939, o ano de sua morte, passando pela produção de outros psicanalistas durante o século XX, até chegar a atualidade.

\section{Evangélicos e homossexualidade}

Autores que pesquisaram as conexões ativas entre religião e homossexualidade no Brasil contemporâneo (Natividade \& Oliveira, 2013; Machado \& Piccolo, 2010; Gomes, 2006) apontam que a produção sobre orientação sexual e religiões cristãs, em especial o 
protestantismo, é modesta quando comparada àquela que se dedica aos cultos afro-brasileiros. Em linhas gerais, essas análises sugerem uma constante rejeição religiosa à diversidade sexual em crenças cristãs. Nas revisões de estudos sobre direitos LGBT, realizada pelos autores supracitados (Natividade \& Oliveira, 2013; Machado \& Piccolo, 2010), evidencia-se o bloqueio sistemático, por parte de atores conservadores religiosos, das iniciativas contra a homofobia e contra a discriminação por orientação sexual e identidade de gênero. Ao mesmo tempo, eles constatam uma complexificação desse cenário social, com a entrada em cena de grupos minoritário spró-direitos, como as chamadas "igrejas inclusivas".

No contexto contemporâneo nacional, de acordo com Gomes (2006), no protestantismo brasileiro, a teologia prática reflete a práxis de cada pastor e vincula-se à tradição denominacional e ao discurso oficial de uma determinada confissão protestante. As representações da sexualidade no protestantismo brasileiro são impingidas por profissionais da fé, pastores e missionários - normalmente norteamericanos ou lá formados (ou, acrescentamos, nas igrejas autóctones, inspirados na mesma tradição), o que confere a esses atores um semblante de especialistas em sexualidade humana, colocando-os como sexólogos insuspeitos perante uma massa de fiéis. Consequentemente, conclui o autor, a pedagogia sexual do protestantismo brasileiro produz as formas apresentadas pelo protestantismo puritano norte-americano representada pela sexualidade da norma, sem nenhuma referência ao prazer, com a finalidade de zelar pela funcionalidade do matrimônio e a procriação. Machado e Piccolo (2010) em pesquisa sobre as relações de gênero, sexualidade e família, percepções sobre diversidade sexual, direitos sociais, violência e homofobia e DST/HIV/AIDS junto a lideranças religiosas evangélicas, católicas, espíritas, afro-brasileiras e judaicas, encontraram obstáculos para o desenvolvimento de seu trabalho impostos por algumas denominações religiosas, mais especificamente a Igreja Universal do Reino de Deus (IURD), a Assembléia de Deus, a comunidade judaica e as lideranças religiosas com cargos no Poder Legislativo. De acordo com a análise realizada por estes autores, os discursos das lideranças religiosas valorizam as perspectivas naturalistas nas concepções da sexualidade - o que em resumo corresponde à sexualidade atrelada às expectativas de papel de gênero atribuídas ao sexo fisiológico, com finalidade de procriação. Também apresentam preocupação em distinguir "dois tipos" de homossexualidade, uma determinada por fatores genéticos e psicológicos e outra caracterizada por uma escolha moral.

Outro achado na pesquisa conduzida por Machado e Piccolo (2010) sugere que entre os evangélicos há acentuado apego à heteronormatividade 4 no ramo pentecostal, embora as interpretações para a homossexualidade sejam diversas. Nesse ramo 
se verifica a tendência das lideranças a apresentarem uma leitura mais literal da Bíblia e de valorização do Antigo Testamento. Essa perspectiva sobre sexualidade apresenta semelhanças com as dos judeus ortodoxos que referenciam as mesmas escrituras. Entretanto, existem diferenças também entre os pentecostais, com algumas lideranças destacando os aspectos espirituais e outras destacando aspectos biológicos, psicológicos e também "problemas de caráter". Entre os protestantes históricos se encontra concepções distintas da sexualidade humana e da homossexualidade, o que ocasiona transformações nesse ramo evangélico, como a existência de um grupo de teólogos luteranos desenvolvendo uma teologia queer ${ }^{5}$ e 0 surgimento das igrejas inclusivas. Para Natividade (2010, p. 93), estas igrejas, que são normalmente chamadas de "igrejas gays", diferenciam-se no campo religioso mais amplo pela criação de cultos em que aos homossexuais é facultada a possibilidade de ocuparem cargos eclesiais sem que seja necessária a ocultação de sua identidade sexual. $\mathrm{O}$ autor observa que estas igrejas parecem indicar a constituição de um mundo social específico, onde as pessoas socializadas em religiões cristãs e que compartilham de uma identidade LGBT podem constituir laços eletivos e permitir o compartilhamento da sua dimensão íntima da vida, frequentemente vivenciados numa situação de relativa clandestinidade, até que elas entrem para essas comunidades inclusivas.

Conforme a análise empreendida pela pesquisadora Fabíola Rohden e equipe (2005), segundo os dados da pesquisa GRAVAD ${ }^{6}$, que não se restringe à esfera religiosa, as mulheres são mais favoráveis à homossexualidade, com exceção das pentecostais. Enquanto os homens se destacam por repudiar a homossexualidade, tal repúdio também é maior entre os homens pentecostais. Grande número dos entrevistados considera que homens que fazem sexo com outros homens "não tem vergonha" ou são "doentes". Natividade e Oliveira (2013), que também comentaram essa pesquisa, chamam a atenção para o fato de essa entrevista ter sido realizada com jovens entre 18 e 24 anos, o que demonstra índices expressivos de rejeição à homossexualidade em uma camada da população mais sensível aos processos de modernização.

Marcelo Natividade e Leandro de Oliveira, antropólogos que há mais de uma década pesquisam sobre homossexualidades e protestantismo no Brasil, possuem uma incontornável obra (2004, 2005, 2008, 2009, 2010, 2013) para as finalidades do presente artigo. Os autores apresentam uma compilação de dados e análises que contribuem para a compreensão da perspectiva evangélica acerca de homossexualidade, a partir da interpretação da pesquisa quantitativa "Novo Nascimento", de 1998, que tinha como objetivo verificar o impacto da religião na vida pública e privada de evangélicos do Rio de Janeiro, conduzida pelo Instituto de Estudos da 
Religião (ISER), e da pesquisa qualitativa e quantitativa conduzida por Machado, em 1996, com católicos carismáticos e pentecostais. Nesse painel analisado pelos autores, destacam-se, em ambas as pesquisas, resistência a mudanças sociais, conservadorismo religioso, demonização da homossexualidade e maior intenção punitiva a homossexuais na Assembleia de Deus, rejeição da homossexualidade, maior acolhimento de homossexuais na IURD, embora este 'acolhimento' possa ser analisado como uma estratégia para maior incorporação de fiéis ao culto (Natividade \& Oliveira, 2013). Sobre esse tipo de "acolhimento", que se revela cruel, podendo também ser lido como espécie de "homofobia pastoral", Natividade e Oliveira (2009), em momento anterior, mas em situação correlata com a demonstrada na pesquisa abordada, fazem a seguinte colocação:

O acolhimento aos homossexuais é a face mais solar de uma estratégia política higienista, agenciada no plano das microrelações cotidianas, que não atinge os sujeitos diretamente com a ameaça da violência física, mas antagoniza e desqualifica sexualidades consideradas indesejáveis. Esta forma de homofobia pastoral apresenta a desqualificação e o expurgar da diferença como uma atitude ativa de cuidado e zelo para com o outro, consonante com a ética cristã (p. 214).

Em outra análise sobre os discursos evangélico e católico sobre homossexualidade, Natividade e Oliveira (2004) identificam três inclinações em relação às concepções de homossexualidade: um discurso afinado com o discurso pentecostal, a homossexualidade como possessão demoníaca a ser solucionada na experiência religiosa; um discurso que porta uma 'visão psicologizante' da homossexualidade; e um discurso inclusivo, que reporta à ideia de ética e de comportamento responsável independente de orientação sexual.

\section{A homossexualidade e a profissão de psicólogo}

A psicologia, enquanto ciência e profissão, responde por excelência pela subjetividade humana. Psicólogos são profissionais com legitimidade para responder sobre uma variada gama de condutas e o próprio fundamento da existência humana. Nesse ramo do conhecimento, falar de subjetividade também é responder pela sexualidade (Cassal, Garcia, \& Bicalho, 2011).

Em relação aos diferentes discursos produzidos na seara da psicologia, a partir da análise das publicações dos Conselhos de Psicologia e do Sindicato dos Psicólogos, Bock (2012) aponta como a noção de fenômeno psicológico sofreu transformações, especialmente 
nas últimas décadas do século passado. Segundo a interpretação da autora, os textos publicados passam a retratar questões sobre "o papel do psicólogo na sociedade, a formação do psicólogo, os diferentes modelos de atuação, as entidades da categoria, o psicólogo como trabalhador, o conceito de atuação psicológica".

No entanto, em contraste com essa análise, a própria autora apresenta o resultado de um survey com psicólogos, que indica uma condição particularmente "tradicional" em suas respostas, que respalda um ideal de "homem natural", "relacionado à ideia de uma natureza humana que obedece a um desenvolvimento previsto, assim como a noção de um homem a-histórico que se autodetermina" (Bock, 2012, p. 23). Dessa convivência de diferentes visões e concepções em um mesmo campo, sem que isso seja necessariamente apanágio da psicologia, bem como uma evidente pluralidade de práticas e discursos nessa disciplina, é possível extrapolarmos análoga variação com relação à homossexualidade.

Em pesquisa sobre a história da homossexualidade no Rio de Janeiro, Belmonte (2009) analisou publicações e realizou levantamento da produção acadêmica do Instituto de Psiquiatria (IPUB) e da Faculdade de Psicologia, ambos da Universidade Federal do Rio de Janeiro (UFRJ), de 1970 a 2000, bem como da Faculdade de Psicologia da Pontifícia Universidade Católica do Rio de Janeiro (PUC-RJ) e na Revista de Saúde Pública da Faculdade de Saúde Pública de São Paulo, no mesmo período. Os achados dessa autora indicam escassa produção sobre o tema da homossexualidade nos campos acadêmicos da psiquiatria e da psicologia no contexto brasileiro ao longo do período das três últimas décadas do século XX. Essa constatação conduz a pesquisa para o exame de outros meios de divulgação psi sobre homossexualidade não restritos ao meio acadêmico e em revistas de psicologia como Rádice, Luta e Prazer e Órgon.

Essa ampliação do leque da pesquisa permitiu à Belmonte (2009) levantar a hipótese da existência de um discurso "contra-ciência", que é a forma com que ela designa a produção dos psicólogos publicada em veículos não universitários e acadêmicos. O discurso "contra-científico", na terminologia adotada por Belmonte, sobre homossexualidade parece transitar entre o discurso acadêmico senso estrito e o campo cultural mais amplo, não obedecendo aos cânones acadêmicos. Na produção "contra-científica" explorada pela autora verifica-se a presença de temas que não eram tratados pela produção científica acadêmica, como sexo e prazer, orgasmo, sexo e política, erotismo e repressão sexual. Enquanto na produção acadêmica, há a prevalência do discurso psicanalítico, que a autora Belmonte atribui ao contexto científico das décadas de 1960 e 1970 nos EUA, com a prevalência de concepções psicanalíticas da homossexualidade que sustentavam o status quo da APA, repercutindo na produção do 
conhecimento psicológico e psiquiátrico daquele país na década de 1970 e na seguinte.

Conforme constatado por Belmonte (2009), os trabalhos a partir dos anos de 1980 começam a mencionar a AIDS. As publicações "contracientíficas" passam a exibir maior diversidade nas questões de gênero - casais masculinos e femininos - e a homossexualidade como forma de liberação da sexualidade, ainda que traga o dualismo homossexual/ heterossexual. Essas publicações também mencionam a "terapia de aversão" com a observação de que esse tipo de procedimento "poderia até levar as pessoas à morte em decorrência da depressão ocasionada por efeito colateral".

\section{Psicologia, religião e Direitos Humanos}

Degani-Carneiro (2013), em sua pesquisa sobre a interseção entre religiosidade e a atuação profissional dos psicólogos no Brasil, aponta para um alinhamento crescente dos Conselhos de Psicologia, a partir da década de 1990 - especialmente com a ascensão do grupo "Cuidar da Profissão" na gestão do Conselho Federal de Psicologia (CFP), nessa época - com a pauta dos movimentos sociais em favor dos direitos humanos. Tal engajamento é notável nas questões sobre diversidade sexual e nas disputas relativas à homossexualidade. Talvez, a maior expressão da aproximação dos Conselhos com a agenda dos direitos humanos acerca desse tema seja a Resolução CFP 01/1999, que "estabelece normas de atuação para os psicólogos em relação à questão da orientação sexual". Segundo esta Resolução:

Art. $1^{\circ}$ - Os psicólogos atuarão segundo os princípios éticos da profissão notadamente aqueles que disciplinam a não discriminação e a promoção e bem-estar das pessoas e da humanidade. Art. $2^{\circ}$ - Os psicólogos deverão contribuir, com seu conhecimento, para uma reflexão sobre o preconceito e o desaparecimento de discriminações e estigmatizações contra aqueles que apresentam comportamentos ou práticas homoeróticas. Art. $3^{\circ}$ - os psicólogos não exercerão qualquer ação que favoreça a patologização de comportamentos ou práticas homoeróticas, nem adotarão ação coercitiva tendente a orientar homossexuais para tratamentos não solicitados. Parágrafo único - Os psicólogos não colaborarão com eventos e serviços que proponham tratamento e cura das homossexualidades. Art. $4^{\circ}$ - Os psicólogos não se pronunciarão, nem participarão de pronunciamentos públicos, nos meios de comunicação de massa, de modo a reforçar os preconceitos sociais existentes em relação aos homossexuais 
como portadores de qualquer desordem psíquica. Art. $5^{\circ}$ - Esta Resolução entra em vigor na data de sua publicação. Art. $6^{\circ}-$ Revogam-se todas as disposições em contrário (Conselho Federal de Psicologia, 1999).

Em 1998, o CFP, após denúncias de movimentos sociais defensores dos direitos LGBT sobre um encontro do Exodus Brasil ${ }^{7}$ em Viçosa, MG - que contou com a presença da psicóloga evangélica Rozangela Justino, profissional marcadamente associada a propostas de psicoterapia de "reversão da homossexualidade" no país - deliberou a criação de um grupo de trabalho com a finalidade de analisar e oferecer subsídios para discutir e fundamentar sobre essa questão (Kahhale, 2011).

A psicóloga Edna Maria Peters Kahhale, uma das formuladoras da Resolução CFP 01/1999, relata a produção desse grupo de trabalho, cuja composição respondia a alguns critérios estabelecidos pelo CFP, qual seja: ter um profissional que pesquisasse na área da diversidade sexual (Paulo Roberto Ceccarelli); profissionais que atendessem em psicoterapia clínica e refletissem sobre diversidade sexual (Maria Rita Kehl e Ricardo Goldemberg); e contato com profissionais que trabalhassem com jovens e orientação sexual, de modo a discutir possibilidades de escolhas, de constituição da sexualidade e opções de exercê-las (Yara Sayão e Edna Kahhale). O grupo foi coordenado por Ana Mercês Bahia Bock (Kahhale, 2011).

O Brasil é o único país do mundo com esse tipo de documento - a Resolução CFP 01/1999. Tal ineditismo, e o próprio teor dessa resolução, também amealham crítica e oposição. Parte da imprensa nacional favorável ao projeto de lei 234/11, protocolado na Câmara Federal pelo Deputado João Campos (PSDB-GO), em 2011, que visava suspender os parágrafos 3o e 4을 da Resolução CFP 01/1999, ou seja, o fulcro do respectivo documento, pautou-se no argumento de o Brasil ser o único país do mundo a possuir instrumento público de regulação profissional com essa singularidade - a de proibir expressamente a "patologização" da homossexualidade por psicólogos. O jornalista Reinaldo Azevedo, à época um dos principais colunistas da publicação semanal de maior circulação no país, a revista Veja, dedicou três artigos em seu blog hospedado no website desse semanário, para se posicionar contra o que ele chama de "intervenção indevida entre paciente e psicólogo" e "patrulha de eventos que os profissionais podem ou não participar", dentre outras colocações. Os títulos desses artigos dão o tom à tese defendida por Azevedo: "Não existe projeto de 'cura-gay'. É pilantragem jornalístico militante", "Você lerá que comissão aprovou projeto de 'cura gay'. É uma falsa notícia e aqui se explica porquê" e "O fim do que nunca existiu! Pressionado por tucanos, deputado retira projeto apelidado pela imprensa e por ativistas de 'cura gay'" 8. 
O Corpo dos Psicólogos e Psiquiatras Cristãos (CPPC) ${ }^{9}$, organização composta majoritariamente por psicólogas evangélicas, se posicionou contra a resolução CFP 01/1999. Quanto a isso, o CFP trabalhou em duas frentes: por um lado, discutindo diretamente com esse grupo; por outro, realizando levantamento bibliográfico mais amplo a fim de demonstrar a inexistência de pesquisa que classifique a homossexualidade como patologia (Kahhale, 2011).

Em contrapartida, a Resolução CFP 01/1999 também repercute positivamente no Brasil e no exterior. Tendo sido traduzida para o espanhol, inglês e francês, além de ter sido divulgada em um congresso de direitos humanos da APA, na Califórnia, EUA. A partir dessa divulgação, a própria APA organizou grupos de estudo para a elaboração de documentos de referência para norte-americanos e canadenses. Outro desdobramento foi a criação de um grupo internacional acerca do tema, dentro da divisão de direitos humanos da APA (Kahhale, 2011). Grupo que contou com a participação de Pedro Paulo Bicalho, psicólogo e professor da Universidade Federal do Rio de Janeiro (UFRJ).

\section{Psicólogas evangélicas e homossexualidade}

A psicóloga evangélica Rozangela Justino se notabilizou por ser tema de reportagens e por conceder entrevistas a veículos de impressa de grande circulação nacional, como a revista Veja, o jornal Folha de São Paulo e o principal telejornal do Sistema Brasileiro de Televisão (SBT). Na totalidade dessas matérias é abordada a prática e o discurso da psicóloga com relação a propostas de "reversão da homossexualidade" ou à "cura gay" e às consequentes repercussões dessa atuação no âmbito profissional e na sociedade. Após uma série de denúncias feitas pelo ativismo LGBT, Justino - à época era membro do CPPC - foi a primeira psicóloga a ser punida com censura pública por infringir o que prescreve a Resolução CFP 01/1999. Nesse episódio, por Justino ser ré primária, não foi aplicada cassação ao seu registro de psicóloga (Bicalho, 2009). Em 2009, a "psicóloga cristã" declarou através de carta aberta à sociedade brasileira, disponibilizada em seu blog ${ }^{10}$, que não mais atenderá às pessoas que "voluntariamente desejam deixar a homossexualidade". Após esse episódio, a visibilidade que Rozangela Justino havia adquirido na imprensa parece ter arrefecido e a psicóloga aparenta ter entrado em período de certo ostracismo no que concerne à sua atuação em propostas de "reorientação da homossexualidade".

No entanto, em 2013, tramitou pela Câmara dos Deputados Federais o supracitado Projeto Decreto Legislativo (PDC 234/11), que visava sustar os parágrafos 3 e 4으 da Resolução CFP 01/1999 e, dessa forma, legitimar intervenções clínicas que visassem "reverter" a 
homossexualidade na prática da profissão de psicólogo, ou seja, autorizar a "cura gay" no Brasil. Essa circunstância trouxe de volta aos holofotes o caso de Rozangela Justino e ensejou diversas discussões públicas acerca do tema.

Posteriormente, entra em cena nas questões relacionadas à "reversão da homossexualidade", a partir de meados dos anos 2000, a psicóloga radicada no Paraná Marisa Lobo (Degani-Carneiro, 2013). Atuando como psicóloga clínica e pastora evangélica, oferece cursos intitulados "Desconstruindo a ideologia de gênero" e "Reorientação cultural" - na divulgação desse último lê-se no canto da página, em letras menores, "reorientação sexual", o que sinaliza para uma das vertentes de atuação dessa profissional. Além de proferir palestras acerca dos temas trabalhados em seus cursos em diferentes congregações evangélicas de todo o Brasil.

A "psicóloga cristã" Marisa Lobo possui aspirações político-partidárias. Filiada ao Partido Social Cristão (PSC/PR) concorreu a uma vaga de Deputada Federal pelo Paraná nas eleições legislativas de 2014, sem obter êxito nesse intento. Vale observar que se trata do mesmo partido (PSC), à época, dos Deputados Federais pelo Rio de Janeiro Jair Bolsonaro ${ }^{11}$ e por São Paulo pastor Marco Feliciano, políticos publicamente notórios por suas posturas homofóbicas e hostis a toda a agenda política de direitos humanos. Nas eleições municipais de 2016, Lobo disputou, pelo partido Solidariedade, uma vaga na câmara dos vereadores de Curitiba, novamente sem conseguir se eleger ${ }^{12}$.

Lobo possui uma série de publicações e de materiais em formato audiovisual de sua própria autoria, como os livros "Ditadura Ideológica de Gênero: descontruindo a família tradicional" e "Sexualidade debaixo da Graça - Homossexualidade: o que a igreja precisa saber" e os audiovisuais "Comportamentos Compulsivos comportamentos doentios que nos afastam de Deus" e "Sexualidade sem tabus: há limites para um casal cristão na cama?", dentre outros 13. Nova e mais reluzente referência entre os profissionais envolvidos em polêmicas de "cura gay", Marisa Lobo tem sido visada pelos Conselhos de Psicologia por exercer a profissão em discordância ao prescrito acerca da homossexualidade pelo CFP. No entanto, a "psicóloga cristã", como a própria profissional se define (Macedo, 2017) segue atuando profissionalmente e difundindo suas convicções sobre sexualidade, mesmo após ter sofrido cassação pelo Conselho Regional de Psicologia do Paraná (CRP/PR), em 2012, em decorrência de ser acusada de oferecer prática e fazer apologia à "cura gay", pena contra a qual recorreu e foi 'absolvida' pelo CFP, em 2015, tendo sua penalidade sido afixada em censura pública pela respectiva autarquia. 


\section{Considerações}

A transformação do cenário religioso brasileiro, a partir do vigoroso aumento da adesão ao evangelismo pentecostal e neopentecostal e da expressiva atuação pública dos seus líderes na política parlamentar, significou que um contingente crescente de profissionais de diversas áreas colocasse sua prática ao serviço das convicções morais e dos interesses corporativos da sua religião. Na Psicologia, esta opção política e científica concedeu particular protagonismo público a profissionais que promovem a abordagem da homossexualidade como patologia, contra o consenso científico e o marco regulatório da disciplina no Brasil. Na sua defesa, se apropriam da linguagem das garantias democráticas e dos direitos humanos para advogar pela sua "liberdade religiosa" e sua "liberdade científica" e interpretam a proibição de oferecer tratamento para abandonar a homossexualidade como uma violação de direitos e como impedimento para o exercício de um labor filantrópico.

Entretanto, os efeitos políticos do ativismo em defesa da "cura gay" e contra a Resolução 01/99 do CFP vão além do direito deste grupo de psicólogos e não se restringem ao dano que práticas desse tipo causam aos sujeitos que a elas se submetem. Sua expressiva atuação faz parte de uma forte reação conservadora à ampliação dos direitos de sujeitos subalternos e ao protagonismo de movimentos feministas, e LGBT por um direito democrático da sexualidade (Rios, 2006).

A resolução CFP 01/99 também tem sido utilizada em contextos que vão além da regulação da prática de psicólogos no Brasil no que diz respeito às questões relacionadas à orientação sexual. Este documento respalda, por exemplo, casos de autorização pela Justiça brasileira de adoção de crianças por casais homoparentais (Macedo, 2017, p. 88).

Finalmente, o valor testemunhal das suas sucessivas ações no legislativo e seu discreto sucesso no âmbito judicial contribuem para a legitimação de vozes empenhadas em perpetuar a visão da homossexualidade como desvio em várias ordens superpostas e articuladas entre si.

No âmbito médico-psicológico promove-se sua repatologização ao construí-la como fato controverso. Ou seja, que a atração por pessoas do mesmo sexo constitua um transtorno ou uma legítima expressão diversidade humana pode ser tratado como uma questão de opinião, bem como os discursos que a declaram conduta antinatural, fruto de um grave trauma e a associam a outras desordens físicas e mentais. $\mathrm{Na}$ ordem moral reciclam-se $\mathrm{o}$ julgamento da homossexualidade como tendência inerentemente decadente e maldosa e sua associação com outras desordens, legitimando-se formas diretas ou veladas de criminalização, violência e discriminação. No plano religioso, reforça uma compreensão 
singular da laicidade do Estado, que preserva a liberdade religiosa como valor absoluto, ao grado de admitir o alinhamento entre políticas estatais ou práticas revestidas de autoridade científica e princípios doutrinários emanados da interpretação de uma verdade com valor de dogma.

A complexidade dessas articulações evidencia a complexidade do fenômeno. O antagonismo que emerge na polêmica em torno da "cura gay", na medida em que estes atores trazem essa pauta para diferentes arenas - a científica, a religiosa, a profissional - não opõe simplesmente ciência e religião, ou atores religiosos contra o Estado laico, mas envolve atores capazes de se localizar estrategicamente de um lado ou de outro dessas dicotomias.

\section{Referências}

Belmonte, P. R. (2009). História da Homossexualidade: ciência e contra-ciência no Rio de Janeiro (1970-2000) (Tese de Doutorado). Casa de Oswaldo Cruz Fiocruz, Programa de Pósgraduação em História das Ciências e da Saúde, Rio de Janeiro, RJ .

Bicalho, P. P. (2009). Terapias de conversão. Recuperado de http:// www. clam. org. br/busca/conteudo. asp?cod $=6212$

Bock, A. M. B. (2012). História da organização dos psicólogos e a concepção do fenômeno psicológico. In A. M. Jacó-Vilela, A. C. Cerezzo, \& H. B. C. Rodrigues (Orgs.), Clio-Psiché hoje: fazeres e dizeres psi na história do Brasil (pp. 13-24). Rio de Janeiro: Centro Edelstein de Pesquisas Sociais. Recuperado de http://books. scielo. org/id/hkyyb

Butler, J. (2000). Corpos que pesam: sobre os limites discursivos do "sexo". In G. L. Louro (Org.), O corpo educado: pedagogias da sexualidade (pp. 110-125). Belo Horizonte: Autêntica.

Carvalho, E. N. de. (2007). O Divã e o altar: cultura psicanalítica e movimento protestante no Brasil (Tese de Doutorado). Museu Nacional do Rio de Janeiro, Programa de Pós Graduação em Antropologia Cultural, Universidade Federal do Rio de Janeiro, Rio de Janeiro, RJ.

Cassal, L. C. B., Garcia, A. M., \& Bicalho, P. P. G. (2011). Psicologia e o dispositivo da sexualidade: biopolíticas, identidades e processos de criação. Psico, 42(4), 465-473.

Ceccarelli, P. R. (2008, Junho). A invenção da homossexualidade. Bagoas - Estudo gays: gênero e sexualidade, 2(2), 71-94.

Ceccarelli, P. R. (2012). O que as homossexualidades têm a dizer à psicanálise. Bagoas - Estudos Gays: gênero e sexualidade, 6(8), 103-123. 
Centro Latino-americano em Sexualidade e Direitos Humanos [Clam]. (2005). Gravidez na adolescência, Gênero e Sexualidade: estudo multicêntrico sobre Jovens, Sexualidade e Reprodução no Brasil. Recuperado de http://www.clam.org.br

Conrad, P. (2007). Continuity: homosexuality and the potential for remedicalization. In P. Conrad, The medicalization of society: on the transformation of human conditions into treatable disorders (pp. 97-113). Baltimore: The John Hopkins University Press.

Conselho Federal de Psicologia [CFP]. (1999). Resolução no 001/99. Estabelece normas de atuação para os psicólogos em relação à questão da Orientação Sexual. Brasília: Conselho Fedral de Psicologia. Recuperado de https://site.cfp.org.br/wpcontent/uploads/1999/03/resolucao1999_1.pdf

Dean, T., \& Lane, C. (2001). Homosexuality and psychoanalysis: an introduction. In T. Dean, \& C. Lane (Eds.), Homosexuality and Psychoanalysis ( $p p$ 4-42). Chicago: The University Of Chicago Press.

Degani-Carneiro, F. (2013). Psicólogos evangélicos: interseção entre religiosidade e atuação profissional em Psicologia no Brasil (Dissertação de Mestrado). Universidade do Estado do Rio de J aneiro, Instituto de Psicologia, Rio de Janeiro, RJ .

Drescher, J. (2013). A história da homossexualidade e a psicanálise organizada. In A. Quinet, \& M. A. C. Jorge (Orgs.), As homossexualidades na psicanálise: na história de sua despatologização (pp. 47-58). São Paulo: Segmento Farma Editores Ltda.

Dunker, C. I. L., \& Kyrillos Neto, F. (2011). A crítica psicanalítica do DSM - IV: breve história do casamento psicopatológico entre psicanálise e psiquiatria. Revista Latino-americana de Psicopatologia Fundamental, 14(4), 611-626.

Foucault, M. (2014). História da Sexualidade 1: a vontade de saber. Rio de Janeiro / São Paulo: Paz \& Terra.

Freud, S. (2006). Três ensaios sobre sexualidade (Vol. 7). Rio de Janeiro: I mago, 2006.

Gomes, A. M. A. (2006). As Representações sociais do corpo e da sexualidade no protestantismo brasileiro. Rever: Revista de Estudo da Religião, 1(6), 1-38.

Green, J. N. (1999). Beyond Carnival: male homosexuality in twentieth-century Brazil. Chicago: The University of Chicago Press.

Heilborn, M. L., \& Gravad, E. (2005). Uniões precoces, juventude e experimentação da sexualidade. In M. M. L Barros, M. L. Heilborn, C. E. Peixoto, \& L. F. D. Duarte (Orgs.), Sexualidade, família e ethos religioso (pp. 39-59). Rio de Janeiro: Garamond Universitária. 
Junqueira, R. D. (2007). O reconhecimento da diversidade sexual e a problematização da homofobia no contexto escolar. In P. R. C. Ribeiro, M. R. S. Silva, N. G. S. Souza, S. V. Goellner, \& J. F. Souza (Orgs.), Corpo, gênero e sexualidade: discutindo práticas educativas (pp. 59-69). Rio Grande: Furg.

Kahhale, E. M. P. (2011). Histórico do Sistema Conselhos de Psicologia e a Interface com questões LGBTs. In Conselho Regional de Psicologia da 6o Região [CRP/SP], Psicologia e Diversidade Sexual: cadernos temáticos CRP/SP (pp. 20-24). São Paulo: CRP/SP.

Kutchins, H., \& Kirk, S. A. (1997). The fall and rise of homosexuality. In H. Kutchins, \& S. A. Kirk, Making us crazy: DSM - the psychiatric bible and the creation of mental disorders (pp. 5599). Nova Iorque: The Free Press.

Lima, L. V. V. (2004). Agentes de Deus: representações sociais dos psicólogos cristãos na prática terapêutica (Dissertação de Mestrado). Universidade do Estado do Rio de Janeiro, Instituto de Psicologia, Rio de Janeiro, RJ .

Louro, G. L. (2000). Pedagogias da sexualidade. In G. L. Louro (Org.), O corpo educado: pedagogias da sexualidade (pp. 734). Belo Horizonte: Autêntica.

Macedo, C. M. R. (2017). A "clínica pastoral" dos psicólogos cristãos no Brasil (Dissertação Mestrado). Universidade do Estado do Rio de Janeiro, Instituto de Medicina Social, Programa de PósGraduação em Saúde Coletiva, Rio de Janeiro, RJ .

Machado, M. D. C., \& Piccolo, F. D. (2010). Religiões e Homossexualidades. Rio de J aneiro: FGV Editora.

Mafra, C. (2001). Os Evangélicos. Rio de Janeiro: Zahar.

Natividade, M. T., \& Oliveira, L. (2004). Algumas tendências recentes nos discursos evangélico e católico sobre a homossexualidade. Sexualidade: gênero e sociedade, 22(11), 1-8.

Natividade, M. T., \& Oliveira, L. (2009). Nós acolhemos os homossexuais: homofobia pastoral e regulação da sexualidade. Tomo, 14(1), 203-227.

Natividade, M. T., \& Oliveira, L. (2013). Diversidade sexual e religião: a construção de um problema. In M. T. Natividade, \& L. Oliveira, As Novas guerras sexuais: diferença, poder religioso e identidades LGBT no Brasil (pp. 39-71). Rio de Janeiro: Garamond.

Natividade, M. (2005). Homossexualidade masculina e experiência religiosa pentecostal. In M. L. Heilbornetal (Org.). Sexualidade, família, e ethosreligioso (pp. 247-272). Rio de Janeiro: Garamond.

Natividade, M. T. (2008). Deus me aceita como eu sou? A disputa sobre o significado da homossexualidade entre evangélicos no Brasil (Tese de Doutorado). Universidade Federal do Rio de 
Janeiro, Programa de Pós-graduação em Sociologia e Antropologia, Rio de Janeiro, RJ .

Natividade, M. T. (2010). Uma Homossexualidade santificada? etnografia de uma comunidade inclusiva pentecostal. Religião e Sociedade, 2(30), 90-121.

Natividade, M. T. (2013). Homofobia religiosa e direitos LGBT: notas de pesquisa. Latitude, 7(1), 33-51.

Nucci, M. F., \& Russo, J. (2009, Janeiro). O terceiro sexo revisitado: a homossexualidade no Archives of Sexual Behavior. Physis: Revista de Saúde Coletiva, 1(19), 127-147.

Quinet, A., \& Jorge, M. A. C. (2013). As homossexualidades na psicanálise: na história de sua despatologização. São Paulo: Segmento Farma Editores.

Rios, R. R. (2006) Para um direito democrático da sexualidade. Horizontes Antropológicos, 26(12), 71-100.

Rohden, F., \& Gravad, E. (2005). Religião e iniciação sexual em jovens de camadas populares. In M. L. Heilbornetal (Org.), Sexualidade, família, e ethos religioso (pp. 177-205). Rio de J aneiro: Garamond.

Russo, J. (2002). O mundo PSI no Brasil. Rio de Janeiro: Zahar.

Russo, J. (2004). Do Desvio ao transtorno: a medicalização da sexualidade na nosografia psiquiátrica contemporânea. In A. Piscitelli, M. F. Gregori, \& S. Carrara (Orgs.), Sexualidades e Saberes: convenções e fronteiras (pp. 95-114). Rio de Janeiro: Garamond.

Russo, J. (2005). A sexualidade no DSM III: Sexualidads, salud y derechos humanos em America Latina. Seminário Regional 2005. Recuperado de www.ciudadaniasexual.org

Russo, J., \& Venâncio, A. T. A. (2006). Classificando as pessoas e suas perturbações: a "revolução terminológica" do DSM III. Revista Latinoamericana de Psicopatologia Fundamental, 9(3), 460-483.

Valle, C. G. (2002). Identidade, Doenças e Organização Social: um estudo das pessoas "vivendo com HIV e AIDS". Horizontes Antropológicos, Porto Alegre, 17(8), 179-210.

\section{Endereço para correspondência}

\section{Cleber Michel Ribeiro de Macedo}

Universidade do Estado do Rio de Janeiro - UERJ

Rua São Francisco Xavier, 524, 60 andar Bloco E, Maracanã, CEP 20550-013, Rio de Janeiro - RJ, Brasil

Endereço eletrônico: cleberribmacedo@gmail.com

\section{Horacio Federico Sívori}

Universidade do Estado do Rio de Janeiro - UERJ

Rua São Francisco Xavier, 524, 60 andar Bloco E, Maracanã, CEP 20550-013, Rio de Janeiro - RJ, Brasil

Endereço eletrônico: hfsivori@gmail.com 
Recebido em: 11/11/2018

Reformulado em: 10/02/2019

Aceito em: 14/02/2019

\section{Notas}

* Psicólogo. Mestre e doutorando em Saúde Coletiva pelo Instituto de Medicina Social da Universidade do Estado do Rio de Janeiro (IMS/UERJ ).

** Professor Adjunto, Instituto de Medicina Social, Universidade do Estado do Rio de Janeiro (IMS/UERJ). Coordenador do Centro Latino-Americano em Sexualidade e Direitos Humanos (CLAM). www.clam.org.br.

${ }^{1}$ Agradecemos à CAPES, FAPERJ E CNPQ ao apoio recebido.

2 Para uma discussão do contexto brasileiro da emergência da AIDS e estigmatização da homossexualidade ver "Identidade, doenças e organização social: um estudo das pessoas "vivendo com HIV e AIDS" (Valle, 2002).

3 Para maior aprofundamento ver "As Homossexualidades na Psicanálise: na história de sua despatologização" (Quinet \& Coutinho, 2013) e "Homosexuality \& Psychoanalysis" (Dean \& Lane, 2001).

4 Em linhas gerais, "em nossa sociedade, a norma que se estabelece, historicamente, remete ao homem branco, heterossexual, de classe média urbana e cristão e essa passa a ser a referência que não precisa mais ser nomeada. Serão os "outros" sujeitos sociais que se tornarão "marcados", que se definirão e serão denominados a partir dessa referência. Desta forma, a mulher é representada como "o segundo sexo" e gays e lésbicas são descritos como desviantes da norma heterossexual" (Louro, 2000).

${ }^{5}$ Conforme nota do tradutor de Butler (2000), "o termo 'queer' tem sido usado, na literatura anglo-saxônica, para englobar os termos 'gay' e 'lésbica'. Historicamente, 'queer' tem sido empregado para se referir, de forma depreciativa, às pessoas homossexuais. Sua utilização pelos ativistas dos movimentos homossexuais constitui uma tentativa de recuperação da palavra, revertendo sua conotação negativa original. Essa utilização renovada da palavra 'queer' joga também com um de seus outros significados, o de 'estranho'. Os movimentos homossexuais falam, assim de uma política queer ou de uma teoria queer".

6 A pesquisa "Gravidez na adolescência: estudo multicêntrico sobre jovens, sexualidade e reprodução no Brasil" (Pesquisa GRAVAD) foi realizada por três centros de pesquisa: Programa em Gênero, Sexualidade e Saúde, do IMS/UERJ, Programa de Estudos em Gênero e Saúde, do ISC/UFBA, e Núcleo de Pesquisa em Antropologia do Corpo e da Saúde de UFRGS (Heilborn \& Gravad, 2005). "A pesquisa GRAVAD versou sobre os seguintes tópicos: história familiar e socialização para a sexualidade, primeiro namoro, as experiências de ficar, iniciação sexual, relacionamentos afetivos e suas rupturas, moralidade sexual, práticas e repertório sexuais com parceiro do sexo oposto ou do mesmo sexo, ocorrência ou não de gravidez e/ou aborto, e vivência da maternidade e paternidade" (Clam, 2005). A pesquisa foi realizada nas capitais Porto Alegre, Rio de Janeiro e Salvador, com jovens entre 18 e 24 anos de idade.

7 Conforme a própria instituição se define, “Exodus Brasil, é o representante do Exodus Global Alliance no país, uma organização Cristã interdenominacional, sem fins lucrativos, com o chamado para unificar e equipar Cristãos para ministrar o poder transformador de Jesus Cristo àqueles de alguma maneira envolvidos na homossexualidade". Fonte: www.exodus.org.br

8 Disponível em http://veja.abril.com.br/blog/reinaldo/tag/conselho-federal-depsicologia/ Acessado em 12/12/2015.

9 O CPPC é uma instituição eminentemente evangélica, que possui alguns poucos filiados católicos (Lima, 2004; Degani-Carneiro, 2013), fundada em 1976, com sede 
no Rio de Janeiro e atualmente com núcleos espalhados por todo o país. O CPPC é reconhecido por fazer uma aproximação explícita entre as diferentes teorias "psi" e a perspectiva cristã (CARVALHO, 2007) e pelo seu pioneirismo no meio evangélico, onde desfruta de popularidade (Degani-Carneiro, 2013) e prestígio (Macedo, 2017). A homossexualidade é tema polêmico dentro desta organização, um profissional filiado ao CPPC, entrevistado por Lima (2004), comenta que a homossexualidade se tornou uma questão "maldita" para o CPPC e motivo para que "persigam" a organização, segundo ele, "não por causa de justiça, mas do pressuposto religioso. É uma questão que a gente deve olhar de uma forma muito cautelosa".

${ }^{10}$ Fonte: rozangelajustino. blogspot.com

${ }^{11}$ Em Janeiro de 2018, Jair Bolsonaro deixou o PSC e se filiou ao Partido Social Liberal (PSL), pelo qual concorreu à Presidência da República nas eleições de 2018 tendo sido eleito presidente do Brasil.

12 Nas eleições legislativas de 2018, Marisa Lobo se lançou novamente candidata a uma vaga à Deputada Federal pelo estado do Paraná, dessa vez pelo partido AVANTE, sem conseguir se eleger. Como em outras de suas candidaturas lê-se em suas peças de campanha "Marisa Lobo Psicóloga Cristã".

13 Disponível em: https://www.psicologiacrista.tudonavitrine.com.br/ Acessado em $10 / 11 / 2017$.

Este artigo de revista Estudos e Pesquisas em Psicologia é licenciado sob uma Licença Creative Commons Atribuição-Não Comercial 3.0 Não Adaptada. 